Abdominal and rectal tenderness were more frequent in this condition, and a palpable mass in the loin or pelvis combined with absence of local swelling in the region of the hip indicated a diagnosis of retroperitoneal infection rather than a septic hip lesion. Radiological investigation often showed an abdominal or pelvic mass or widening of the psoas shadow.

Similar diagnostic problems may arise in acute osteomyelitis of the pelvis. A. Morgan and A. K. Yates ${ }^{2}$ drew attention to the fact that patients with osteomyelitis of the pelvis may present with symptoms and signs in the hip, but, as in retroperitoneal abscess, there is differential limitation of hip extension and medial rotation. In some patients the lesion presented as an abdominal syndrome with clinical features simulating acute appendicitis on the right side and paracolic abscess on the left. Laparotomy, with removal of a normal appendix, was recorded on a number of occasions. Other patients with osteomyelitis of the pelvis may present with pain in the buttock or sciatica. Radiographic findings are late in appearing, and the infection may be well established and involve a large area of bone before any changes are recognizable. Even when the whole clinical picture indicates the presence of a large abscess, it may be difficult to discover where it is and even more difficult to drain it surgically.

In contrast, septic arthritis of the hip presents with painful limitation of hip movement in all directions and with local swelling and tenderness over the joint only. Osteomyelitis of the pelvis involving the innominate aspect of the joint may simulate almost completely the signs of septic arthritis. But critical examination should allow the true source of sepsis that may be masquerading as a lesion of the hip to be discovered.

\footnotetext{
1 March, A. W., Riley, L. H., and Robinson, R. A., fournal of Bone and

Foint Surgery, 1972, 54-A, 67.
2 Morgan, A., and Yates, A. K., Postgraduate Medical fournal, 1966, $42,74$.
}

\section{Cancer Research: Preparing for a Long Haul}

During the last few years the aura of ballyhoo surrounding cancer research in Britain has faded. Talk of finding "the answer" to what was wrongly presumed to be but a single question is far less in evidence, and words like "breakthrough" are heard less often. Several factors have helped to bring about these welcome changes, and one of them is the reorganization and modernization of the Cancer Reresearch Campaign. The 49th Annual Report of the Campaign $^{1}$ covering the year 1971 , published this week, is in the new form adopted for the first time last year. Two-thirds of the 143-page report is taken up by lists of titles of research projects and of publciations by research workers supported by the Campaign. Much of the remainder is necessarily concerned with financial matters and a report of the opening on 18 November 1971 of the Gray Laboratory at Mount Vernon Hospital, Middlesex, by Mr. Jack Hawkins. The laboratory is in reality an extension of the research unit in radiobiology which was opened in 1957 and whose first director was Dr. L. H. Gray. Research in the enlarged laboratory will not, however, be restricted to radiobiological studies.

Included in the report are general reviews of three aspects of cancer research. The first of these is by Sir Richard Doll and Dr. L. J. Kinlen and is concerned with epidemiology as an aid to determining the causes of cancers. Much of the content is well known, but snippets of information scattered here and there make it necessary and worthwhile to read the whole. Thus not everyone will know that the skin cancers which the early radiobiologists developed were mainly on the backs of the hands, that the risk of cancer from asbestos began 100 years ago with the discovery of deposits of chrysotile in Canada and Russia, that "Chutta cancer" of the palate in Vizagapatam is attributable to the local habit of smoking cigars with the lighted end inside the mouth, or that a rapid rise in the incidence of oesophageal cancer in parts of eastern and central Africa seems to be associated with the recent introduction into those areas of a method of preparing beer by the fermentation of maize. But perhaps the most important development mentioned in this article is the starting, with the support of the Campaign, of a prospective epidemiological survey of patients receiving immunosuppressant drugs for the prevention of graft rejection after transplantation surgery or for other reasons. There is already evidence that recipients of kidney grafts are more likely to develop lymphomas, reticulum-cell sarcomas, ${ }^{23}$ and a variety of other neoplasms ${ }^{4}$ than persons of comparable ages in the general population. However, it is not certain whether the increased risk is attributable solely to the prolonged exposure of the recipients of tissue grafts to immunosuppressant drugs or whether the presence of foreign proteins (antigens) for long periods is itself a factor that favours the development of cancer. Some evidence from experiments on laboratory animals suggests that continued antigenic stimulus may predispose to the development of neoplasms. ${ }^{5}$ The possibility that neoplasia result from activation of oncogenic viruses where there is both antigenic stimulation and immunosuppression has recently been discussed. ${ }^{6}$

In the 1972 Walker prize lecture at the Royal College of Surgeons Mr. Denis Burkitt ${ }^{7}$ propounded a theory that the low-roughage diets consumed by Europeans and North Americans predispose to constipation, diverticulitis, and cancer of the lower bowel. The prolonged residence of material in the gut might, he thought, permit carcinogens to be formed by the bacterial degradations of bile salts and give such carcinogens time to act on the cells lining the gut.

Professor R. E. O. Williams and his colleagues ${ }^{8}$ at St. Mary's Hospital, London, recently reported different concentrations of steroids and differences in gut flora between persons living in communities where colon cancer is common and persons living in communities where it is rare. There is a natural aversion among research workers to studying faecal matter, and methods for studying gut bacteria are poorly developed. Nevertheless, the fact that more enzymic activity takes place within the gut and the gut wall than in the liver 9 should long ago have directed the attention of cancer biochemists to the urgent need for more factual information about the contents of the intestines.

In their up-to-date review of the chemical causes of cancer Professor P. N. Magee and Dr. A. E. Pegg look again at Walter Burdette's conclusion, written in 1955,10 that "a general correlation between mutagenicity and carcinogenicity cannot be proposed from present evidence." As Burdette himself realized, the failure of carcinogenic chemicals to induce mutation in higher organisms may be due to a failure of the administered substance or its active metabolite to reach the germ cells. Similarly the failure of a mutagen to induce cancer may mean no more than that the administered substance or its active metabolite did not reach a carcinogen-sensitive target. Magee and Pegg stress the im- 
portance of metabolic conversion of inactive precursors to active carcinogens and thereby imply that the relationship between carcinogenicity and mutagenicity may be closer than it is at present fashionable to believe. Elsewhere they produce a motto suitable for the wall of every cancer testtube-ologist: "Although studies with cells in culture may provide much significant information, it is essential that such investigations of the mechanism of carcinogenesis be extended to the whole living organism."

In the third review article, Professor G. Hamilton-Fairley summarizes the achievements of cancer chemotherapy and stresses the importance of using agents in the ways in which they are most effective. The problem of drug resistance can sometimes best be overcome by high-dose intermittent therapy or by the use of a battery of agents in a cyclical rotation.

At just over $£ 2,600,000$ the income of the Campaign during 1971 was $4.4 \%$ up on that for 1970 . A sum not far short of this was used to support 20 large institutions and 94 individual research workers. For many years the United Kingdom's subscription to the International Union Against Cancer (U.I.C.C.) has, regrettably, fallen short of the full amount. It is heartening, therefore, to learn that the Cancer Research Campaign and the Imperial Cancer Research Fund have each agreed to pay half the $£ 10,000$ due in 1972 . These payments will be made through the British Cancer Council, which forms the official link with the U.I.C.C.

The new chair in Medical Oncology at St. Bartholomew's Hospital endowed by the Imperial Cancer Research Fund ${ }^{11}$ is matched by the endowment of a similar chair at the Institute of Cancer Research by the Cancer Research Campaign. But the swing of the pendulum towards more clinically orientated research is clearly not yet complete. The Campaign announced this week its decision to establish several more similar university chairs over the next 10 years at a capital cost of $£ 2 \mathrm{~m}$.

1 Cancer Research Campaign, 49th Annual Report 1971. London, Cancer Research Campaign, 1972.

2 Doak, P. B., Montgomerie, J. Z., North, J. D. K., and Smith, F., British Medical fournal, 1968, 4, 746.

3 Schneck, S. A., and Penn, I., Lancet, 1971, 1, 983.

4 Penn, I., Malignant Tumours in Organ Transplant Recipients, p. 1. Berlin, Springer-Verlag, 1970.

5 Shwartz, R. S., and Beldotti, L., Science, 1965, 149, 1511.

6 Shwartz, R. S., and Beldotti, L., Science,

7 Burkitt, D., Epidemiology and Causation of Bowel Cancer. The Walker Prize Lecture of the Royal College of Surgeons of England delivered at the Royal College of Surgeons on 9 May 1972.

8 Hill, M. J., et al., Lancet, 1971, 1, 95.

9 Drasar, B. S., Hill, M. J., and Williams, R. E. O., in Metabolic Aspects of Food Safety, ed. F. J. C. Roe, p. 245. Oxford, Blackwell, 1970.

10 Burdette, W. J., Cancer Research, 1955, 15, 201.

11 British Medical fournal, 1972, 2, 63.

\section{Behaviour Disorders and Public Safety}

Psychopathic personality as a legal concept is neatly defined in the Mental Health Act, 1959. But in clinical practice the concept loses definition and spills over into a wide range of behaviour disorders, some of them mild and reversible, others severe and irreversible. Common to all psychopaths, in varying degrees, is an incapacity to experience guilt for their misdeeds: they are, therefore, amoral rather than immoral. To them self-fulfillment can be brought about only by self-indulgence. It is a measure of the perversity of human nature that in some psychopaths self-fulfillment finds expression in the destruction of fellow human beings.
An extreme, possibly unique, case of psychopathic personality is evinced in Graham Frederick Young, who murdered by poisoning two of his work-mates and endangered the lives of several others. There is nothing to be gained by the repetition of all the macabre details. What is especially pertinent from a medical or medicolegal standpoint is that Young, still only 24 years of age, was committed to Broadmoor Hospital at the age of 14 for the attempted murder of his father, sister, and a school-friend by poisoning, using methods as subtle as those he employed a decade later. That his preoccupation with toxicology and its application as a means of destroying human life still persisted is evident. But then this is with the benefit of hindsight.

His admission to Broadmoor was with a restriction on discharge for a period of 15 years. Yet in early 1971 on the recommendation of a highly experienced psychiatrist he was conditionally discharged by the Home Secretary in the hope that he could be rehabilitated and so take his place again in society. That the psychiatric prognosis was ill-founded and the conditions for supervision in the community tragically inadequate are chronicled in the events that followed.

Public opinion is understandably alarmed by this disaster, and the demand for stricter safeguards in order to prevent a repetition must be met. The Home Secretary has already taken certain positive steps. In a statement to the House of Commons" he said that "no patient is now discharged from the special hospitals until the responsible medical officer who has supervised the patient's treatment has obtained a concurring recomendation from another consultant psychiatrist experienced in this particular work." What is not stated is whether the second opinion is to be obtained from a consultant on the staff of the same hospital or from elsewhere. The embarrassment that can arise from disagreement between colleagues from the same hospital seems all too obvious. Moreover, prognosis cannot be an exact science, and in the event of a disagreement who is to act as the final arbiter? The statement goes on, "the arrangements for supervision, including psychiatric supervision, have been strengthened; and arrangements have been made to ensure that, where necessary, the supervising officer is in touch with the employer and the employer is sufficiently informed about the case to be in a position to tell the supervisor of any incident giving rise to anxiety." That such a recommendation, vitally important as it is, cuts across accepted ethical considerations relating to confidentiality is something with which the medical profession will have to come to terms. It is possible that the written consent of the patient to a full disclosure of his case to parties interested in his rehabilitation would suffice. This is not too great a price to pay for freedom, a freedom that has to be balanced against the safety of society.

In addition, the Home Secretary has set up two committees which include leading jurists and doctors, one to see that the procedures as now improved are satisfactory or whether there are further changes that should be made within the existing law, and the other to review the criminal law in relation to the mentally abnormal offender.

All these legislative steps are to be welcomed as an earnest of the Home Secretary's intent. But no amount of legislation can instil infallibility into psychiatric judgement. What is to be hoped meantime is that there will be no overreaction such as to jeopardize the discharge from special hospitals of patients who after treatment pose no threat to society.

1 House of Commons Hansard, 29 June 1972, col. 1863. 